\title{
The Effectiveness of Virtual Labs in Engineering Education- What do we measure?
}

\author{
Anita S Diwakar ${ }^{1}$, Santosh B. Noronha ${ }^{2}$ \\ Department of Educational Technology, \\ Indian Institute of Technology Bombay. Mumbai, India \\ 12anitasd@iitb.ac.in,2noronha@che.iitb.ac.in
}

\begin{abstract}
The effectiveness of any educational technology depends on the perceptions of faculty and students about its utility or value addition in teaching and learning. In this paper we identify the criteria considered to contribute to the effectiveness of virtual labs after a literature review. There are numerous studies, which focus on the evaluation of usability of e-learning content. There are very few studies, which focus on the utility of technology in the teaching learning process. We carried out a study with engineering faculty and students to find out their perception about the criteria for effectiveness of virtual labs. Then we compare the criteria from literature review and the perception studies and come up with the most important criteria contributing to the effectiveness of the new technology labs.
\end{abstract}

\footnotetext{
Anita S Diwakar

Department of Educational Technology,

Indian Institute of Technology Bombay. Mumbai, India

anitasd@iitb.ac.in
}

There are various studies, which report the effectiveness of virtual labs after carrying out experimental or quasi-experimental designs. Most of the studies report the effectiveness of the new technology labs based on the performance of students in a written exam. We propose a new technique to measure the effectiveness of virtual labs based on ABET criteria for engineering laboratory education and affordances of the pedagogical features of the lab. We present the reports of a study carried out with UG Electrical engineering students using the proposed technique to measure effectiveness.

Keywords: virtual labs, effectiveness metric, learning objectives, engineering skills

\section{Introduction}

For any new technology such as virtual labs to be useful in education it must be both usable and hold utility for teaching and learning. It must add some value to the process of teaching and learning that is; it must be effective. Effectiveness is the capability of producing a desired result. When something is deemed effective, it means it has an intended or expected outcome, or produces a deep, vivid impression. "Efficiency is doing things right, while Effectiveness is doing the right things." This is based on the premise that selection of objectives of a process 
is just as important as the quality of that process. There are various studies, which report the effectiveness of virtual labs after carrying out experimental studies and surveys. Each of the study uses a different parameter for the effectiveness metric. In the first section of this paper we present a study, which aims at finding out the perceptions of the faculty and students of engineering colleges from the Mumbai state university at diploma, degree and post-graduate level about the effectiveness of virtual labs. We review the prior related work to find out the parameters, which have been reported to be contributing to the effectiveness of virtual labs. Then we compare these two sets of parameters contributing to effectiveness and come up with a list of factors, which contribute to the effectiveness of virtual labs.

The paper is organized in four sections. The first section gives the details of the Virtual lab effectiveness metric. In the second section of the paper we propose a technique to measure the effectiveness of virtual labs and present results of a Pilot study carried out with UG engineering students implementing the proposed technique. Finally we discuss the further work, which is going to be carried out to establish the usefulness of the technique.

\section{Effectiveness Metric}

\section{A. Related Work}

The analysis of 14 papers spanning over five years from 2007 to 2011 from the journal Computers and Education with studies on Virtual labs was carried out to find out the criteria considered for effectiveness of these labs. Of these 14 studies; three are one group exploratory, six are two group quasi-experimental studies and two are qualitative studies. There are three papers, which just describe the implementation process and have not carried out any study with students or faculty. The sample sizes vary from a small size of 9 to larger sizes of 247 and 363. The Fig. 6 on page 7 gives the detailed analysis of the papers [1-10]. We identified several factors, which the authors consider as parameters contributing to the effectiveness of virtual labs, and the instruments used. The following Table 1. gives the analysis of the instruments used in the related work and Table 2. gives the effectiveness parameters identified.

\section{A. Perceptions of Students and Faculty Study}

In order to find out the perceptions of engineering
Table 1. Instruments Used in Related Work

\begin{tabular}{|c|l|c|}
\hline \multicolumn{1}{|c|}{ Instruments used } & No. of Papers \\
\hline 1 & Survey Questionnaire & 7 \\
\hline 2 & Performance of students in final semester test & 2 \\
\hline 3 & Laboratory report & 1 \\
\hline 4 & Performance of students in pre-post tests & 6 \\
\hline 5 & Survey Questionnaire+ Performance in test & 5 \\
\hline \multicolumn{2}{|c|}{ Table 2. Effectiveness Parameters } & No. of Papers \\
\hline S.No & \multicolumn{1}{|c|}{ Effectiveness Parameter } & 7 \\
\hline 1 & Suitability of virtual lab in learning concepts & 3 \\
\hline 2 & Student's Preparation of tasks in physical labs & 2 \\
\hline 3 & Understand theory behind experiment, emphasis on team work and support pre-lab training & 2 \\
\hline 4 & Foster Self-regulated learning & \\
\hline 5 & Achievement of Student's learning outcomes & \\
\hline
\end{tabular}

students and faculty about effectiveness of virtual labs a study was carried out. The research question addressed in this study is

RQ1: What are the perceptions of engineering students and faculty members regarding the parameters contributing to the effectiveness of virtual laboratories?

A total of 113 UG engineering students and 37 faculty members participated in the study. In order to gather the perceptions of the faculty at diploma and degree level engineering workshops were conducted at the premises of the institutes. The researcher initially gave a 30-minute presentation to the participants describing the virtual labs and then they were asked to work with the virtual labs in their domain for about an hour. They were asked to perform one experiment in the virtual lab with simulation. This was done so that the participants could find out the difference in the two lab formats and experience the new lab. After they had performed one experiment a written consent was taken from the participants so that the researcher can use the data of the survey. After obtaining the consent the survey questionnaire was administered. They were given enough time to fill up the survey. The survey questionnaire had twelve questions of which ten questions were with a five point likert scale format and two open ended questions. All the twelve questions were based on the effectiveness metric. The survey instrument was developed using the standard development procedure followed for research purposes. The researcher prepared a draft of the survey after a literature review of the existing instruments. Most of the existing ones had questions related to other Technology Enhanced Learning metrics of Attractiveness, Accessibility and Efficiency. A few surveys had questions related to 
parameters contributing to effectiveness metric. This draft was then submitted to a panel of three domain experts from engineering colleges for comment and review. The panel suggested certain changes, which were incorporated, and then again a review carried out. The product was finalized after a consensus was reached that the instrument was satisfying the validity criteria.

The data collected from the survey was analyzed to find out the percentage agreement among the faculty members and students about the parameters they perceive will contribute to the effectiveness of virtual labs in teaching learning process. The following table gives the percentage agreement of faculty.

In the two open ended questions they were asked to comment on the parameters contributing to the effectiveness of the virtual labs and the reason why they considered it important. A content analysis was carried out for the data gathered from these two questions. The following Table 3 . gives the results of the survey giving the list of parameters, which were considered lead to the effectiveness of virtual labs as tools for students learning process and faculty's teaching and percentage agreement by faculty and students.

\begin{tabular}{|c|c|c|c|}
\hline \multicolumn{4}{|c|}{ Table 3. Effectiveness Parameters From The Study } \\
\hline $\begin{array}{l}\text { S. } \\
\text { No }\end{array}$ & $\begin{array}{c}\text { Effectiveness Parameter (As per the } \\
\text { literature analysis) }\end{array}$ & $\begin{array}{r}\% \text { of } \\
\text { Faculty }\end{array}$ & $\begin{array}{l}\% \text { of } \\
\text { Students }\end{array}$ \\
\hline 1 & Suitability of virtual lab in learning concepts & 85 & 75 \\
\hline 2 & $\begin{array}{l}\text { Student's Preparation of tasks in } \\
\text { physical labs }\end{array}$ & 60 & 80 \\
\hline 3 & $\begin{array}{l}\text { Understand theory behind experiment, } \\
\text { emphasis on team work and support pre } \\
\text { lab training }\end{array}$ & 100 & 95 \\
\hline 4 & Foster Self- regulated learning & 93 & 90 \\
\hline 5 & Achievement of Student's learning outcomes & 96 & 85 \\
\hline $\begin{array}{l}\text { S. } \\
\text { No }\end{array}$ & $\begin{array}{l}\text { Effectiveness Parameter (As per the } \\
\text { Survey questionnaire) }\end{array}$ & $\begin{array}{r}\% \text { of } \\
\text { Faculty }\end{array}$ & $\begin{array}{c}\% \text { of } \\
\text { Students }\end{array}$ \\
\hline 1 & The features of the virtual labs & 70 & 85 \\
\hline 2 & $\begin{array}{l}\text { The tasks students perform while } \\
\text { working with the virtual labs }\end{array}$ & 86 & 90 \\
\hline 3 & $\begin{array}{l}\text { The process through which the students } \\
\text { go through while working with these labs }\end{array}$ & 76 & 65 \\
\hline 4 & $\begin{array}{l}\text { The learning of students using virtual } \\
\text { labs over a period of time }\end{array}$ & 92 & 95 \\
\hline 5 & Assessment of tasks in virtual labs & 75 & 100 \\
\hline 6 & $\begin{array}{l}\text { Duration of time the students spend } \\
\text { working with virtual labs }\end{array}$ & 70 & 75 \\
\hline 7 & $\begin{array}{l}\text { Alignment of task with the learning } \\
\text { outcome }\end{array}$ & 86 & 70 \\
\hline 8 & $\begin{array}{l}\text { Feedback provided to the students while } \\
\text { performing the tasks in virtual labs }\end{array}$ & 76 & 40 \\
\hline
\end{tabular}

\section{A. Comparison of the Effectiveness Metric Parameters}

After a comparison of the results obtained from the literature review and perception studies with engineering faculty and students the following parameters need to be considered while evaluating the effectiveness of virtual lab as a teaching and learning tool. 1. The features of the virtual labs 2.The tasks students perform while working with the virtual labs 3.The process through which the students go through while working with these labs 4.The learning of students using virtual labs over a period of time 5.Assessment of tasks in virtual labs 5.Duration of time the students spend working with virtual labs 6.Alignment of task with the learning outcome 7.Suitability of virtual lab in learning concepts 8.Student's Preparation of tasks in physical labs 9.Understand theory behind experiment, emphasis on team work and support pre-lab training 10.Foster Selfregulated learning 11.Achievement of Student's learning outcomes 12.Feedback provided to the students while performing the tasks in virtual labs.

The next section describes the development of the technique to measure the effectiveness of virtual labs in engineering. The above parameters were considered and accordingly incorporated in the design and development of the technique.

\section{Vlab Effectiveness Measurement Technique}

In most of the studies with online labs the effectiveness is measured by means of the performance of the students only after the training is over. The lab is said to be effective if the performance of the students in post-test or final semester exam is improved. Sometimes the lab report submitted is graded and the lab is considered to be effective if the students submit the report complete in all respects. So the product of learning is assessed and not the way in which it occurs. Also the performance measure may not necessarily point to the learning objectives of the lab. Jodie Jenkinson (2009) points out that success of any new technology is measured in terms of student performance, as demonstrated by tests assessing factual recall and knowledge of basic concepts. The author suggest that such measures may tell us what new knowledge is being learned but does not tell us anything about how new knowledge has developed. We propose a technique by which we measure the effectiveness of the vlab by measuring the students learning in the lab while they are performing the lab work.

When students work with the virtual labs it is possible to measure the variables, which give the 
progress of learning; that is; how does learning proceed from one task to another as they perform one experiment after the other. This way we are measuring whether the learning objectives are met as per the ABET criteria and also whether the students are engaged in the lab learning process.

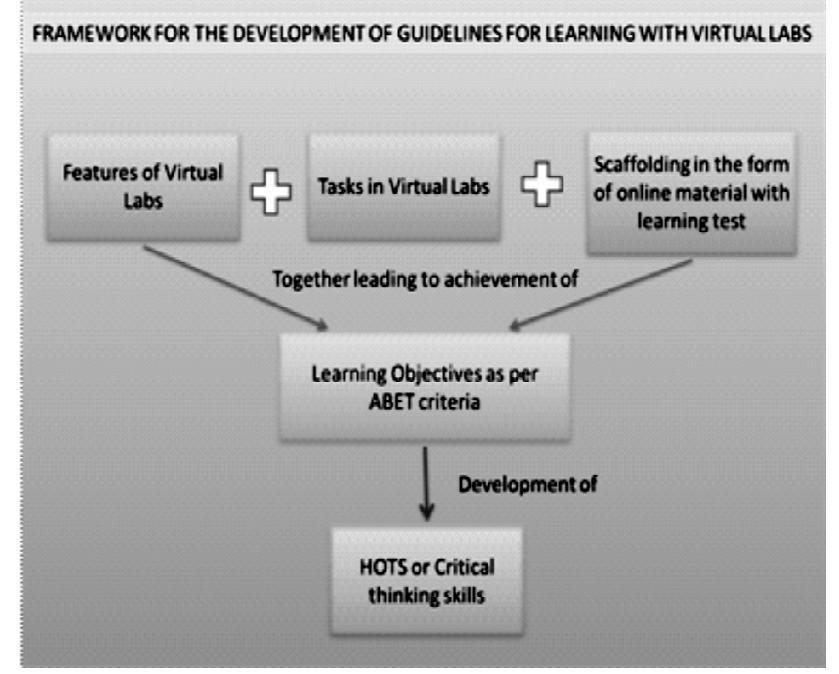

Fig. 1.Fig. 1 Theoritical Framework for the Development of CTS using Virtual Labs

The following thirteen learning objectives criteria were identified by ABET after the colloquy on Learning Objectives for Engineering Education Laboratories, Lyle D. Feisel, George D. Peterson, Watson School of Engineering, State University of New York at Binghamton/Executive Director, Accreditation Board for Engineering and Technology was held in the year 2002. 1. Instrumentation 2. Models 3. Experiment 4. Data Analysis 5. Design 6. Learn from Failure 7. Creativity 8. Psychomotor 9. Safety 10. Communication 11. Teamwork 12. Ethics in the Lab 13. Sensory Awareness [16].

\section{A. Virtual Lab Learning Process Measurement Technique}

We have based the technique on two educational technology theories the Biggs Constructive Alignment [17] and cognitively principled assessment design. The Fig. 1 illustrates the Constructive Alignment Framework [12] used to design the tasks given to the students while working with virtual labs and Fig. 2 gives one example for Basic Electronics course.

Edys S. Quellmalz, (2013) lists the features of effective formative assessment within the cognitively principled assessment design. The steps in this design are:

1) 1. Specification of the learning progressions and goals for instruction

2) 2. Specify the knowledge and processes to be measured during instruction

3) 3. Elicit evidence of the learning during instruction with embedded assessments and feedback

4) 4. The planned assessments would also include activities that engaged students in self-assessment and collaboration with other students and the teacher

In order to measure the learning that happens when students perform experiments using vlab the devised technique consists of following steps:

\section{Selection of the course}

口 Selection of the Virtual lab

口 Identification of the features of selected Virtual lab

口 Selection of the suitable ABET criteria

口 Mapping of $A B E T$ criteria with learning objectives for the selected course

口 Development of tasks as per the learning objectives

口 Breaking down the tasks into activities

u Development of questions to be asked after each activity

( Development of Rubrics for assessing the activities

4 Development of the online material incorporating

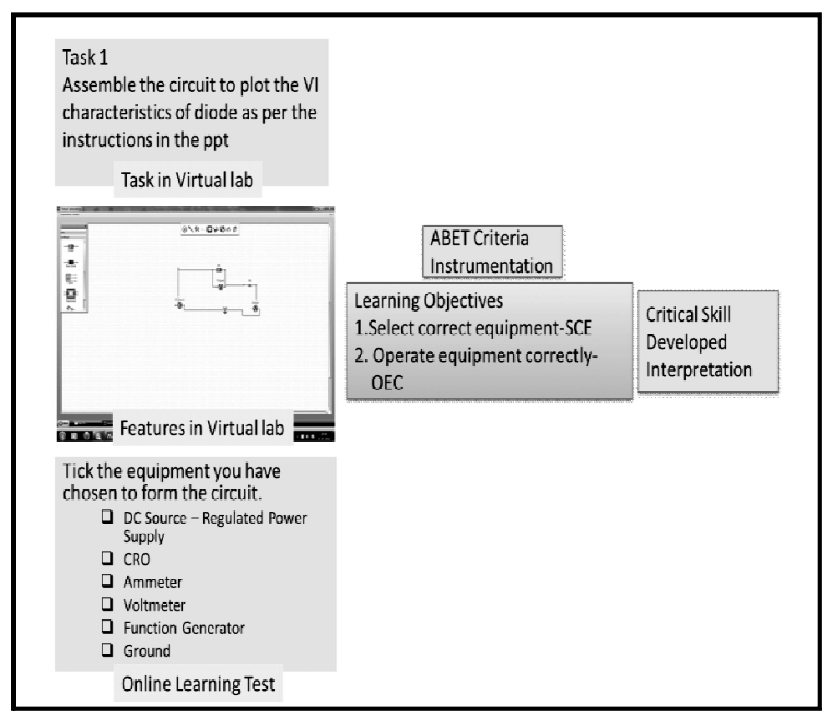



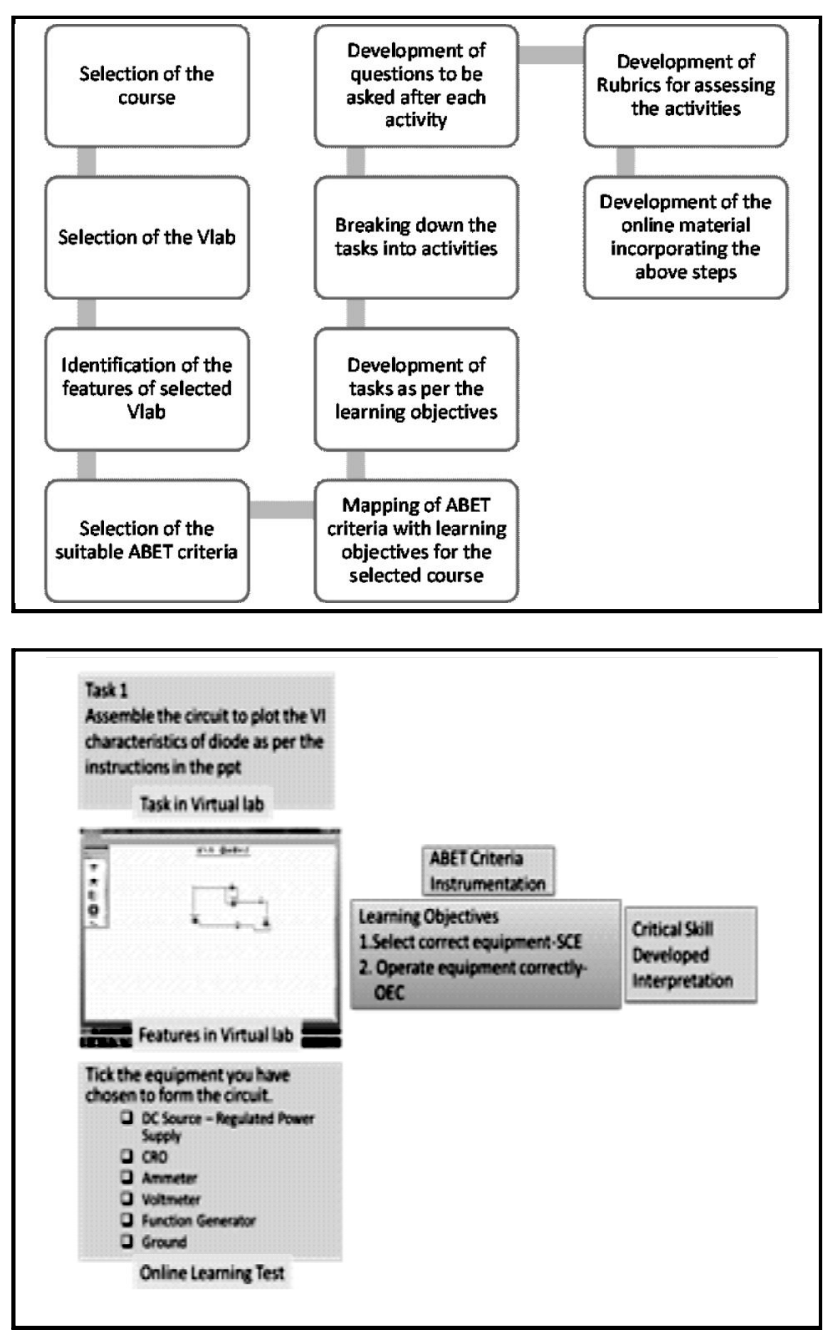

Fig. 1.Fig. 2 Sample Example

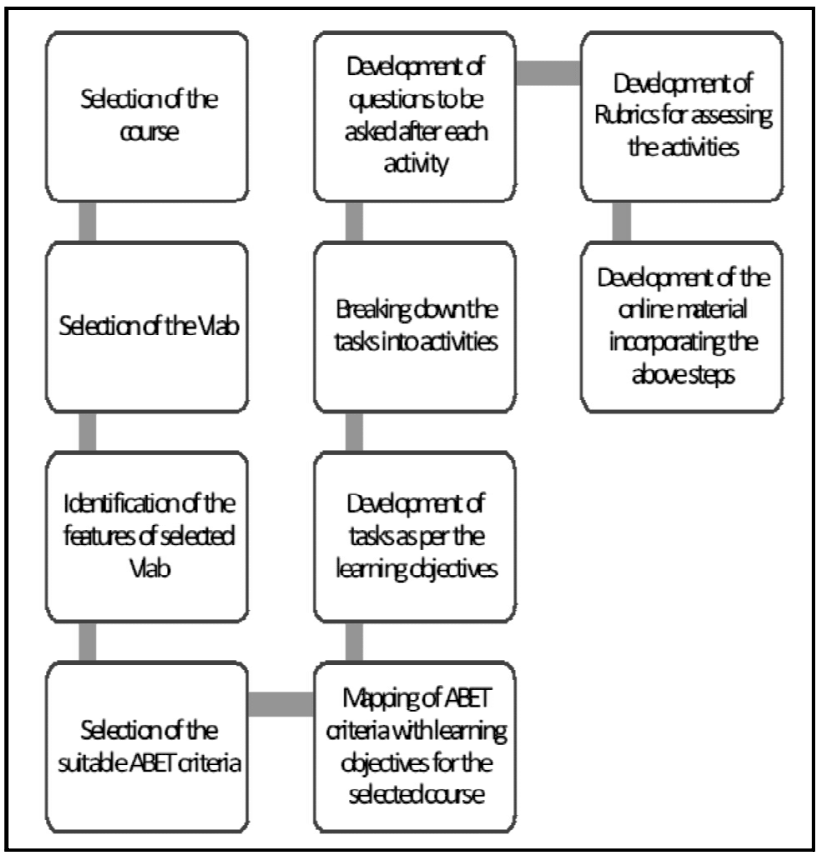

Fig. 1.Fig. 3 Steps followed in the technique
The above Fig. 3 illustrates the details of the proposed technique.

1) Selection of the course: The author has been working as faculty in the Electronics Engineering UG domain for the last 23years and hence the Basic and Advanced Electronics course is selected being the fundamental course in this domain.

2) Selection of the Virtual lab: The Virtual Labs project is an initiative of Ministry of Human Resource Development, India under the National Mission on Education through ICT (NME-ICT). Under this project eleven institutes have developed two types of instructional labs - Virtual labs with Simulation and Remote Triggered Hardware labs in nine engineering domains. The virtual lab selected for the purpose of this study is the Basic and Advanced Electronics lab developed by IIT Kharagpur.

3) Identification of the features of selected Virtual lab: After the selection of the virtual lab the features of this lab were identified. The tasks and activities that can be allotted to the students very much depend on these features. The features of the selected lab are Background Theory, Procedure, Pre-test, Circuit diagram, Drag and drop components and equipment, Setting the specifications of components and equipment, Exhaustive list of components available, Form circuits, Simulate circuits as per settings, Automated graph plotting, Varying the $\mathrm{X}$ and $\mathrm{Y}$ axes parameters, Background Theory and Procedure.

4) Selection of the suitable ABET criteria: From the features available in the virtual lab the learning objectives, which can be achieved using this lab, are identified. They are Instrumentation, Experiment, Model, Data Analysis and Debug.

5) Mapping of $A B E T$ criteria with learning objectives (LO) for the selected course: The ABET criteria are very broad terms which need to be operationalized to suitable measurable variables. These are the dependent variables of the study. After the students perform experiment using the vlab these variables will be measured. If the values obtained are above a certain pre-determined thresh-hold then it can be considered as the achievement of that objective.

6) Development of tasks as per the learning objectives: In order to achieve the selected LOs the students are assigned certain larger tasks. The students need to complete these tasks in the allotted time. If the 
students complete the task then the LO is said to be achieved.

7) Breaking down the tasks into activities: The tasks allotted are larger ones and not directly measurable. So they are broken down into smaller tasks called activities. After the completion of each activity the students have to answer a question, which is either a MCQ, or an open-ended question.

8) Development of questions to be asked after each activity: The questions asked after the end of each activity are designed such that they target the particular LO. Different types of questions are designed such as MCQ, Numerical problems, openended questions etc.

9) Development of Rubrics for assessing the activities: The grading of MCQs and Numerical problems is easy but for the open-ended questions it is difficult. So Rubrics are designed for grading the open-ended questions.

10) Development of the online material incorporating the above steps: The last step in the design of the techniques was to develop the online material, which is given to the students while they are performing the experiment. The students are required to submit the answers to the assessment questions to the instructor once they complete the experiment.

\section{A. Implementation of the Technique}

- In order to find out the effectiveness of the virtual lab a pilot study was carried out with five students in which we try to answer the research questions:

RQ2: How does the learning with virtual labs change over time?

- RQ3: What are the features of and tasks in virtual labs, which contribute to the effectiveness of virtual labs?

- The five participants of the Pilot study were second year engineering students from Electronics branch from a self-financed engineering educational institute.

- The students had been taught the topics in the class by the faculty and they had performed experiment using the traditional lab with breadboard, components, wires and equipment. The students were appraised about virtual labs and given a demo of one experiment by the researcher. Then the students worked with virtual labs for nearly two hours and performed the experiment on the same topic. The students were given the online material developed consisting of the Learning Test questions. The students had to complete the test while performing the experiment.

u The same procedure was followed for all the five experiments.

$\square$ After the students have completed the performance of experiments along with the completion of test questions in the online material it is submitted to the instructor. In the Pilot study presented the author worked as the instructor and graded the test questions. The online material calculates the total grades obtained in each of the task based on the grades in each of the activities.

\section{B. Results}

A semi-automatic process graded the students. Each task has many activities and each activity is assigned marks. The marks obtained in a particular task is sum total of the marks obtained in each of the questions after each activity. The online material assesses some of the questions automatically while the instructor assesses some after the students have submitted the learning test. The following Table gives the sample of the marks allotment template.

\section{Fig. 1.Fig. 4 Grading of Tasks}

The Fig. 4 illustrates the grading metric used for a particular task based on the student's answers to the questions after each activity in the task. Though the answers are graded after the students have submitted the material the students write the answers while they are performing the various tasks and thus this leads to a formative assessment for the students. If the students give an incorrect answer they are given a feedback. This helps the students to understand the tasks where they need an improvement.

Each experiment has tasks with graded activities based on the learning objectives mapped as per the ABET criteria. The following Table 4. gives the grades obtained by one of the students who performed the experiments in the pilot study and Fig. 5 illustrates the graph showing progression of the student as he performs the experiments one after the other. 


\begin{tabular}{|c|c|c|c|c|c|c|c|}
\hline Expt1 & $\begin{array}{c}\text { V-I } \\
\text { Characteristics } \\
\text { of Diode }\end{array}$ & Task 1 & $\begin{array}{c}\text { A } \\
1\end{array}$ & $\begin{array}{c}\text { A } \\
\text { L }\end{array}$ & $\begin{array}{c}\text { A } \\
3\end{array}$ & $\begin{array}{c}\text { TM } \\
\text { T1 }\end{array}$ \\
\hline $\begin{array}{c}\text { ABET } \\
\text { Criteria }\end{array}$ & $\begin{array}{c}\text { Learning } \\
\text { Objective }\end{array}$ & $\begin{array}{c}\text { Assemble } \\
\text { the circuit. } \\
\text { Draw the } \\
\text { assembled } \\
\text { circuit }\end{array}$ & & & & & \\
\hline $\begin{array}{c}\text { Instrume } \\
\text { ntation }\end{array}$ & $\begin{array}{c}\text { Select correct } \\
\text { equipment-SCE }\end{array}$ & & & & & & \\
\hline & $\begin{array}{c}\text { Operate } \\
\text { equipment } \\
\text { correctly-OEC }\end{array}$ & & & & & & \\
\hline & & & & & & & \\
\hline & & & & & & & \\
\hline & & & & & & \\
\hline
\end{tabular}

TABle 3. Marks Of STUdent 1 In VARIOUS TASKS OF EXPERIMENT 1

\begin{tabular}{|l|l|c|}
\hline S.No. & \multicolumn{1}{|c|}{ Task } & Marks \\
\hline 1. & Task 1 & 9 \\
\hline 2. & Task 2 & 9 \\
\hline 3 & Task 3 & 6 \\
\hline 4. & Task 4 & 5 \\
\hline 5. & Task 5 & 6 \\
\hline 6. & Task 6 & 3 \\
\hline 7. & Task 7 & 2 \\
\hline
\end{tabular}

The tasks are assigned such that each of the next tasks requires higher order thinking than the previous. It can be observed from the marks obtained that; in the first experiment the student is able to score higher in the initial tasks but the marks are reduced as he

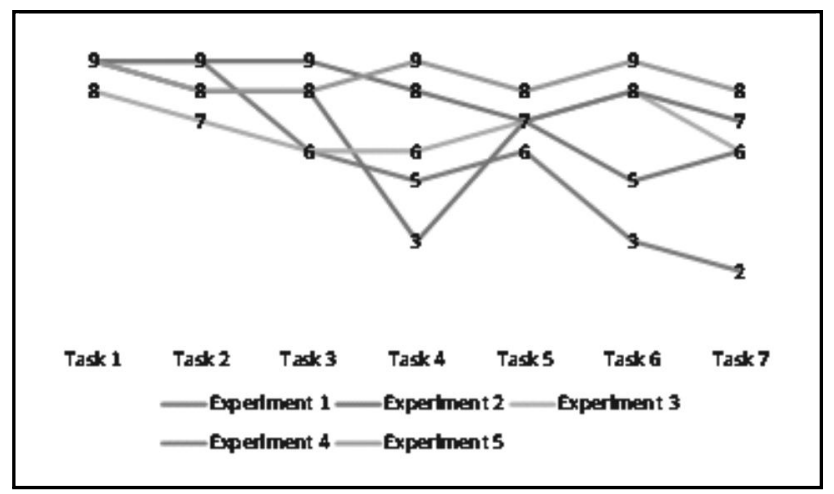

progresses in the higher order tasks.

Fig. 1.Fig. 5 Student performance in the tasks as he progresses from experiment 1 to experiment 5

From Fig. 5 it can be seen that as the student progresses with the experiments he is able to score more in the higher order tasks. The scores in higher tasks for experiment 5 are much higher than in
Table 5. Features of Virtual Lab Used

\begin{tabular}{|c|c|c|c|c|c|c|c|}
\hline $\begin{array}{l}\text { Experi } \\
\text { ment } 1\end{array}$ & $\begin{array}{c}\text { Task } \\
1\end{array}$ & $\begin{array}{c}\text { Task } \\
2\end{array}$ & $\begin{array}{c}\text { Task } \\
3\end{array}$ & $\begin{array}{c}\text { Task } \\
4\end{array}$ & $\begin{array}{c}\text { Task } \\
5\end{array}$ & $\begin{array}{c}\text { Task } \\
6\end{array}$ & $\begin{array}{c}\text { Task } \\
7\end{array}$ \\
\hline F1 & $\mathrm{Y}$ & $\mathrm{N}$ & $\mathrm{N}$ & $\mathrm{N}$ & $\mathrm{Y}$ & $\mathrm{N}$ & $\mathrm{N}$ \\
\hline F2. & $\mathrm{Y}$ & $\mathrm{N}$ & $\mathrm{N}$ & $\mathrm{N}$ & $\mathrm{Y}$ & $\mathrm{N}$ & $\mathrm{N}$ \\
\hline F3 & $\mathrm{Y}$ & $\mathrm{N}$ & $\mathrm{N}$ & $\mathrm{N}$ & $\mathrm{Y}$ & $\mathrm{N}$ & $\mathrm{N}$ \\
\hline F4. & Y & $\mathrm{N}$ & $\mathrm{N}$ & $\mathrm{N}$ & $\mathrm{Y}$ & $\mathrm{N}$ & $\mathrm{N}$ \\
\hline F5. & $\mathrm{N}$ & $\mathrm{Y}$ & $\mathrm{N}$ & $\mathrm{N}$ & $\mathrm{Y}$ & Y & $\mathrm{Y}$ \\
\hline F6. & $\mathrm{N}$ & $\mathrm{Y}$ & $\mathrm{Y}$ & $\mathrm{Y}$ & $\mathrm{Y}$ & $\mathrm{Y}$ & $\mathrm{Y}$ \\
\hline F7. & $\mathrm{N}$ & $\mathrm{Y}$ & $\mathrm{Y}$ & $\mathrm{Y}$ & $\mathrm{Y}$ & $\mathrm{Y}$ & $\mathrm{Y}$ \\
\hline F8. & $\mathrm{Y}$ & $\mathrm{N}$ & $\mathrm{Y}$ & $\mathrm{Y}$ & $\mathrm{Y}$ & $\mathrm{Y}$ & $\mathrm{Y}$ \\
\hline F9 & $\mathrm{Y}$ & $\mathrm{Y}$ & $\mathrm{N}$ & $\mathrm{N}$ & $\mathrm{Y}$ & $\mathrm{N}$ & $\mathrm{N}$ \\
\hline
\end{tabular}

experiment 1 whereas the scores in the lower order tasks remain nearly same. Similar graphs are obtained for all the five students except one for whom the scores are higher for most of the tasks. The scores in some of the tasks are very low. In order to take care of this the students perform the experiment again before their final practical examination.

\section{A. Features of Virtual Lab}

The Fig. 6 gives the detailed analysis of the features used by the student per experiment. This gives an understanding about what are the features in the Virtual lab which lead to achieving the desired learning objectives and hence are instrumental in the development of the higher order thinking skills.

1) Drag and drop components and equipment-F1

2) Setting the specifications of components and equipment-F2

3) Exhaustive list of components available-F3

4) Form circuits-F4

5) Simulate circuits as per settings -F5

6) Automated graph plotting-F6

7) Varying the $X$ and $Y$ axes parameters $-F 7$

8) Background Theory-F8

\section{Conclusion}

The pilot study conducted with five undergraduate students delves into how the Virtual labs can be used to develop higher order skills amongst the students and how effectiveness of the new technology labs can 
be measured and improved using the technique based on the two theories of Biggs constructive alignment and cognitively principled formative assessment.

Thus instead of just measuring the learning gains in the form of a post-test which is the most commonly used instrument in educational technology interventions we propose the new technique based on previously established theories. This technique has benefits from student as well as instructor perspective.

\section{A. Benefits from Student Perspective}

The student's lab work in traditional labs is assessed on the basis of the lab write-ups submitted after the completion of the experiment. The instructor may not assess it immediately but much later and the students do not get timely feedback. The marks allocated to a particular lab course work depend on the marks obtained in the write-ups. The assessment is summative and hence whether the students have achieved the desired lab learning objectives cannot be established. They are not assessed based on the various tasks they perform and learning gained. The following are the benefits of the technique

\section{( Fair assessment.}

\section{Learning gain measured.}

After the student completed all the experiments the author took semi-structured interviews of the students. The questions asked were as follows: 1 . Which of the features of virtual labs you feel contributed to your learning in the virtual lab? 2. Do you feel the virtual labs are suitable for the development of higher order thinking skills?

All the five students pointed out that the most important feature of these labs were Exhaustive list of components available, Form circuits, setting the specifications of components and equipment and automated graph plotting. They felt that due to these they could reflect on their learning and find out reasons for the behaviour of component in a particular manner when their internal parameters are varied. The tasks allocated made them think which usually does not happen in case of the traditional labs. They found the feedback component in the online material very useful in order to complete a given task successfully.

\section{B. Benefits from Instructor Perspective}

In many institutes the same lab write-ups are carried over for many years and students refer to the older ones for completing their own. They are also likely to resort to plagiarism. Many times the students submit the write-ups of all experiments at the end of the semester.

1) They can assign different tasks to different students thus avoiding plagiarism.

2) The assessment is semi-automatic and so the work load of instructor reduced.

\section{Further Work}

The technique is tested by carrying out a pilot study with five students. The authors propose to carry out further studies using the Virtual lab in Basic and Advanced Electronics along with the developed online material with undergraduate engineering students in the next semester. These will be longitudinal studies spanning across six months in which the students will perform all the experiments with virtual labs and the results obtained will then be used to modify the online material with the learning tests. The online material is under revision and there will be more features added such as hints to the students while they are performing the experiments. These hints or scaffolds will help students in identifying their mistakes while performing the experiments so that they will get correct results from the assessment questions.

\section{Acknowledgment}

This work has been supported by the Project Virtual Labs under the National Mission on Education through Information and Communication Technology (NMEICT) sponsored by Ministry of Human Resource Development (MHRD), India. We would like to thank Dr. Neena Thota for her guidance on the theoretical framework.

\section{References}

[1] Nickerson, J. V., Corter, J. E., Esche, S. K., and Chassapis, C. (2007) A model for evaluating the effectiveness of remote engineering laboratories and simulations in education, Computers \& Education, 49, 708-725.

[2] Sun, K., Lin, Y., and Yu, C. (2008) A study on learning effect among different learning styles in a Web-based lab of science for elementary school 
students, Computers \& Education, 50, 1411-1422.

[3] Dalgarno, B., Bishop, A. G., Adlong, W., and Bedgood, D. R. (2009) Computers \& Education Effectiveness of a Virtual Laboratory as a preparatory resource for Distance Education chemistry students, Computers \& Education, 53(3), 853-865.

[4] Jara, C. A., Candelas, F. A., Torres, F., Dormido, S., Esquembre, F., and Reinoso, O. (2009) Computers \& Education Real-time collaboration of virtual laboratories through the Internet, Computers \& Education, 52(1), 126-140.

[5] Potkonjak, V., and Vukobratovi, M. (2010) Computers \& Education Virtual Mechatronic / Robotic laboratory e A step further in distance learning, Computers \& Education, 55(2), 465-475.

[6] Abdulwahed, M. and Nagy, Z. K. (2011) Computers \& Education The TriLab, a novel ICT based triple access mode laboratory education model, Computers \& Education, 56(1), 262-274.

[7] Corter, J. E., Esche, S. K., Chassapis, C., Ma, J., and Nickerson, J. V. (2011) Computers \& Education Process and learning outcomes from remotely-operated, simulated, and hands-on student laboratories, Computers \& Education, 57(3), 2054-2067.

[8] Fabregas, E., Farias, G., Dormido-canto, S., Dormido, S., and Esquembre, F. (2011) Computers \& Education Developing a remote laboratory for engineering education, Computers \& Education, 57(2), 1686-1697.

[9] Mikropoulos, T. A. and Natsis, A. (2011) Computers \& Education Educational virtual environments $\square$ : A ten-year review of empirical research (1999-2009), Computers \& Education, 56(3), 769-780.
[10]Rutten, N., Van Joolingen, W. R., and Van Der Veen, J. T. (2012) Computers \& Education The learning effects of computer simulations in science education, Computers \& Education, 58(1), 136-153.

[11]De, D. M., Gómez-estern, F., and Dormido, S. (2012) Computers \& Education A new internet tool for automatic evaluation in control systems and programming, Computers \& Education, 59(2), 535-550.

[12]Quellmalz, E. S. (2013) Technology to support next-generation classroom formative assessment for learning, WestEd, San Francisco, CA, 1-12; h t t p : / / w w w. w e s t e d. or g/w p content/files_mf/1378512875Formative_Assess ment_report4.pdf[Accessed on 26-11-2015].

[13]Freitas, S. and Neumann, T. (2009) "The use of 'exploratory learning' for supporting immersive learning in virtual environments", Computers \& Education, 52(2), 343-352.

[14]Chen, S. (2010) The view of scientific inquiry conveyed by simulation-based virtual laboratories, Computers \& Education, 55(3), 1123-1130.

[15]Jenkinson, J. (2009) Measuring the Effectiveness of Educational Technology $\square$ : what are we Attempting to Measure $\square$ ?, Electronic Journal of e-learning. 7(3), 273-280.

[16]Feisel, L. D. and Peterson, G. D. (2002) A Colloquy on Learning Objectives For Engineering Education Laboratories, In Proceedings of the 2002 American Society for Engineering Education Annual Conference \& Exposition, 16-19.

[17]Donker, A. S., de Boer, H., Kostons, D., Dignath van Ewijk, C. C., and van der Werf, M. P. C. (2014) Effectiveness of learning strategy instruction on academic performance: A metaanalysis, Educational Research Review, 11,1-26. 